\title{
Hubungan Atribut Produk Dengan Keputusan Membeli Kosmetik Oriflame Pada Mahasiswa Fakultas Psikologi Universitas Medan Area
}

\section{The Relationship Products Attribution With Decision Of Buying Oriflame Cosmetics In Students Faculty Of Psychology Universitas Medan Area}

\author{
Harfiah* Syafrizaldi** \\ *Universitas Medan Area , Indonesia \\ *E-mail: harfiah@gmail.com ${ }^{* *}$ E-mail: svaf.rizaldi.csr@gmail.com
}

\begin{abstract}
Abstrak
Penelitian ini bertujuan untuk mengetahui hubungan antara kepribadian extraversion dengan minat berwirausaha. Hipotesis yang diajukan dalam penelitian ini adalah adanya hubungan positif antara kepribadian extraversion dengan minat berwirausaha, dengan asumsi semakin extraversion kepribadian yang dimiliki individu, maka semakin tinggi minat berwirausaha, dan sebaliknya semakin lemah kepribadian extraversion yang dimiliki individu, maka semakin rendah minat berwirausaha. Subjek penelitian yang digunakan dalam penelitian ini adalah mahasiswa-mahasiswi Fakultas Ekonomi Universitas Dharmawangsa Medan sebanyak 125 orang yang dipilih dengan metode purposive sampling. Data diperoleh dari skala untuk mengukur kepribadian extraversion dan minat berwirausaha. Perhitungan dilakukan dengan melakukan uji prasyarat analisis (uji asumsi) yang terdiri dari uji normalitas dan uji linearitas. Analisis data yang digunakan adalah menggunakan korelasi Product Moment melalui bantuan SPSS 15 for Windows. Hasil analisis data menunjukkan koefisien korelasi sebesar 0,535 (p < 0.05). Ini menunjukkan ada hubungan positif antara kepribadian extraversion dengan minat berwirausaha. Hasil penelitian ini menunjukkan bahwa sumbangan yang diberikan variabel kepribadian extraversion terhadap minat berwirausaha adalah sebesar 28,6 persen, selebihnya 72,4 persen dipengaruhi oleh faktor lain seperti self efficacy, locus of control, lingkungan keluarga, pengetahuan kewirausahaan, dan motivasi berprestasi. Dari hasil penelitian ini dapat ditarik kesimpulan bahwa hipotesis penelitian ada hubungan positif antara kepribadian extraversion dengan minat berwirausaha dapat diterima.
\end{abstract}

Kata Kunci: Atribusi Produk; Keputusan Membeli; ;Mahasiswa

\begin{abstract}
This study aims to see the relationship of product attributes with the decision to buy cosmetics for Student Universitas Medan Area, where the subjects of the study were female students aged 18-24 years users of Oriflame Cosmetics at Psychology Faculty at Universitas Medan Area and who match with criteria as many as 67 students. The hypothesis proposed in this study is there is a relationship between product attributes with the decision to buy cosmetics Students Psychology Faculty at Universitas Sumatera Utara, where the assumption is the better attributes of products provided consumers the the greater decision to buy cosmetics and vice versa. The tools used by Semantic Scale Defferensial and Likert Scale. Semantic scale is used to measure products attribute while Likert Scale is used to measure the decision to buy cosmetic. The result show that attribute product indicates $46 \%$ and the rest as $54 \%$ influenced by another variable outside the research.
\end{abstract}

Keyword: Product Attribution; Decision of Buying; Student College

How to Cite: Harfiah \& Syafrizaldi. 2017. Hubungan Atribut Produk dengan Keputusan Membeli Kosmetik Oriflame pada Mahasiswa Fakultas Psikologi Universitas Medan Area, Jurnal Diversita, 3 (1): 25-31. 


\section{PENDAHULUAN}

Mahasiswa merupakan bagian dari remaja akhir. Menurut Erik Erikson (dalam Hurlock, 1980) identitas diri yang dicari remaja berupa usaha untuk menjelaskan siapa dirinya, apa peranannya dalam masyarakat dengan berbagai cara seperti menggunakan simbol status dalam bentuk mobil, pakaian dan pemilikan barangbarang lain yang mudah terlihat menjadi cara remaja menarik perhatian pada diri sendiri agar di pandang sebagai individu.

Sebutan sebagai mahasiswa tetunya perlu proses dari awalnya siswa menjadi mahasiswa. Pakaian bebas yang dikenakan sebagai mahasiswa tentunya pakaian yang sopan dan bersih, Selain pakain hal yang cukup penting untuk menunjang penampilannya yaitu kosmetik. Hal tersebut sesuai dengan pengamatan yang dilakukan terhadap mahasiswa wanita Fakultas Psikologi Universitas Medan Area. Kosmetik menjadi suatu kebutuhan seharihari yang tidak terlepas bagi para wanita yang menggemarinya. Menurut Fabricant \& Gould (dalam Ferrinadewi, 2005) Kosmetik merupakan produk yang unik karena selain produk ini memiliki kemampuan untuk memenuhi kebutuhan mendasar wanita akan kecantikan sekaligus seringkali menjadi sarana bagi konsumen untuk memperjelas identitas dirinya secara sosial dimata masyarakat.

Kosmetik yang sering terlihat dipakai oleh mahasiswa wanita psikologi sehariharinya di kampus yaitu make-up. Salah satu jenis alat make-up yang dipakai yaitu bedak, eyeliner, mascara, lipstik atau lipgloss dan pensil alis. Kosmetik yang dipakai menambah penampilan tersebut menjadi kelihatan lebih cantik. Menurut Synnott (dalam Vidyarini, 2007) kecantikan selalu dikaitkan dengan kebahagiaan, kebenaran, kebaikan, sifat positif, dan utamanya ditekankan pada wajah, maka tentulah perlu kosmetik untuk mendukung.

Untuk membeli kosmetik yang digunakan, konsumen cukup mendatangi member oriflame dan memesan barang sesuai gambar yang ada di katalog oriflame. Pemesanan barang yang dilakukan merupakan bagian dari keputusan membeli. Keputusan pembelian merupakan suatu hak yang dimiliki konsumen. Menurut Peter dan Olson (dalam Sangadji \& Sopiah, 2013), "pengambilan keputusan konsumen adalah pemecahan masalah yang diarahkan pada sasaran ." lebih lengkap lagi, Peter dan Olson menyebutkan bahwa "inti dari pengambilan keputusan konsumen (consumer decision making) adalah proses pengintegrasian yang mengkombinasikan pengetahuan untuk mengavaluasi dua perilaku alternatif atau lebih, dan memilih salah satu diantaranya." Pengambilan keputusan konsumen meliputi semua proses yang dilalui konsmen untuk mengenali masalah, mencari solusi, mengevaluasi alternatif, dan memilih diantara pilihan-pilihan.

Sebelum melakukan keputusan pembelian, tentunya konsumen mencari terlebih dahulu informasi mengenai suatu produk dari beberapa jenis merek yang ada dipasaran. Informasi tersebut di dapat konsumen dari teman, keluarga dan juga iklan yang dipasarkan. Selain pertimbangan merek sebelum membeli, konsumen juga mempertimbangkan kemasan produk, kualitas serta harga yang ditawarkan. Pertimbangan ini yang disebut dengan atribut produk. Kotler dan Amstrong (dalam Hidayat, Elita , Setiaman, 2012) 
menyatakan bahwa atribut produk adalah pengembangan suatu produk atau jasa melibatkan penentuan manfaat yang akan diberikan. Manfaat ini dikomunikasikan dan diserahkan melalui atribut produk yang meliputi kualitas, fitur dan desain (rancangan).

Atribut produk dianggap menjadi stimuli pemasaran yang dapat dijadikan daya tarik serta faktor yang dianggap penting oleh konsumen sebelum membeli suatu produk. Stimuli pemasaran ini menjadi suatu bentuk komunikasi yang berwujud fisik produk untuk mempengaruhi konsumen. Selain itu atribut produk dapat pula menjadi salah satu unsur yang dijadikan andalan dalam memperebutkan konsumen. Tampilan atribut produk yang menarik ini yang akhirnya diharapkan mampu membangun persepsi konsumen untuk membeli.

\section{METODE PENELITIAN}

Populasi adalah wilayah generalisasi yang terdiri atas : obyek / subyek yang mempunyai kualitas dan karakteristik tertentu yang ditetapkan oleh peneliti untuk dipelajari dan kemudian ditarik kesimpulan (Sugiyono, 2008). Adapun yang menjadi populasi dalam penelitian ini adalah mahasiswa wanita Fakultas Psikologi Universitas Medan Area yang memakai kosmetik oriflame sebanyak 67 orang. Sampel adalah bagian dari jumlah dan karakteristik yang dimiliki oleh populasi tersebut (Sugiyono, 2008) Berdasrkan jumlah populasi mahasiswa yang memamkai kosmetik oriflame sebanyak 67 orang, maka yang menjadi sampel dalam penelitian ini adalah sebanyak 67 orang,
Tehnik analisis data dalam penelitian ini adalah tehnik korelasi product moment dari Pearson. Korelasi product moment yaitu tehnik yang digunakan untuk mengetahui hubungan antara dua variabel penelitian yang meliputi variabel bebas dan variabel terikat.

Untuk menguji validitas dan reliabilitas, sebelumnya dilakukan analisis data dengan menggunakan tehnik analisis product moment, maka terlebih dahulu dilakukan uji asumsi yaitu :

a. Uji Normalitas, yaitu untuk mengetahui apakah distribusi data penelitian masing-masing variable telah menyebar secara normal.

b. Uji Linearitas, yaitu untuk mengetahui apakah variable terikat memilki hubungan yang linier dengan variable bebasnya.

Semua data penelitian dilakukan dengan sistem komputerisasi dengan menggunakan program statistik paket SPSS version 17.0 for Windows.

\section{HASIL DAN PEMBAHASAN}

Uji normalitas sebaran ini adalah untuk membuktikan bahwa penyebaran data penelitian yang menjadi pusat perhatian. Uji normalitas sebaran dianalisis dengan menggunakan formula one sample kolograf-smirnov test. Berdasarkan analisis tersebut, maka diketahui bahwa data variabel atribut produk dan keputusan membeli mengikuti sebaran normal, yaitu berdistribusi normal. Sebagai criterianya apabila $p>0,050$ maka sebarannya dinyatakan normal, sebaliknya apabila $\mathrm{p}<$ 0,050 sebarannya dinyatakan tidak normal. 
Tabel 1. Uji Normalitas

\begin{tabular}{|l|c|c|c|c|c|}
\hline Variabel & $\mathbf{X}$ & SD & K-S & P & Ket. \\
\hline $\begin{array}{l}\text { Variabel } \\
\text { Keputusan } \\
\text { Membeli }\end{array}$ & 76,4 & 8,09 & 0,105 & 0,064 & Normal \\
\hline
\end{tabular}

Keterangan :

$\begin{array}{lll}\text { RERATA } & =\text { Nilai rata-rata } \\ \mathrm{K}-\mathrm{S} & =\text { Koefisien } \\ & \text { Kolmogorov-Smirnov } \\ \mathrm{SB} & =\text { Simpangan } \quad \text { Baku } \\ & \text { (Standart Deviasi) } \\ \mathrm{P} & =\text { Peluang Terjadinya } \\ & \text { Kesalahan }\end{array}$

Uji linieritas hubungan dimaksudkan untuk mengetahui derajat hubungan antara variable bebas dengan variable terikat, Tabel 2. Uji Korelasional

\begin{tabular}{|c|c|c|c|}
\hline KORELASIONAL & $\begin{array}{c}\mathrm{F} \\
\text { Beda }\end{array}$ & $\begin{array}{c}\mathrm{p} \\
\text { Beda }\end{array}$ & Keterangan \\
\hline $\mathrm{X}-\mathrm{Y}$ & 55.507 & 0,000 & Linier \\
\hline
\end{tabular}

Keterangan :

$\mathrm{X}=$ Peran Kelompok Teman Sebaya

$\mathrm{Y}=$ Sikap Terhadap Perilaku Seksual

$\mathrm{F}$ BEDA = Koefisien linieritas

$\mathrm{p}$ BEDA = Proporsi peluang ralat

Berdasarkan hasil perhitungan

Metode Analisis Korelasi Product Moment, diketahui bahwa terdapat hubungan positif yang signifikan antara atribut produk dengan keputusan membeli, dimana $r_{x y}=$ 0,$678 ; \mathrm{p}=0.000<0,05$. Artinya semakin baik atribut produk maka semakin besar keputusan membeli, sebaliknya semakin buruk atribut produk maka semakin kecil keputusan membeli. Berdasarkan hasil penelitian yang dilakukan pada Mahasiswa Fakultas Psikologi Universitas Medan Area, maka hipotesis yang telah diajukan dinyatakan diterima.

Dari uraian-uraian di atas, khususnya dari hasil penelitian ini, maka hal yang di perhatikan mahasiswa saat akan membeli suatu produk adalah membuat atribut sendiri pada produk yang akan di beliny artinya apakah atribut produk dapat membentuk keputusan membeli.

Berdasarkan uji linieritas, dapat diketahui apakah variabel bebas dengan variabel terikat dalam penelitian ini dapat atau tidak dianalisis secara korelasional. Hasil analisis menunjukkan bahwa antara variabel bebas atribut produk mempunyai hubungan yang linier terhadap variable terikat keputusan membeli. Sebagai kriterianya apabila $\mathrm{p}$ beda $<0,05$ maka dapat dinyatakan mempunyai derajat hubungan yang linier. Nilai-nilai hubungan tersebut dapat dilihat pada tabel dibawah ini.

Atribut produk itu meliputi, merek, harga, kualitas, desain, kemasan dan label. Diawali dengan mengenal atribut pada merek maka seseorang akan memutuskan untuk membeli, karena merek dapat menyampaikan citra produk tersebut baik atau buruk. Hal tersebut di dukung menurut teori Suryani (dalam Nurfitriani, Wijanarko, Priyatama, 2012) citra suatu merek yang ada di dalam benak konsumen timbul karena proses persepsi yang pada hakikatnya merupakan proses psikologis yang dimulai dari adanya aktivitas memilih, mengorganisasi dan menginterpretasi sehingga konsumen dapat membeikan makna atau nilai atas suatu produk. Selain itu, atribut harga dan kualitas juga menjadi hal yang penting diperhatikan konsumen, walaupun memiliki pandangan berbeda antara harga dan kualitas, tetapi keduanya sering di sandingkan saat akan memutuskan membeli, Menurut North, Vos, dan Kotzé (dalam Kusmayasari, Kumadji, Kusumawati, 2014) harga dan kualitas memiliki efek yang berbeda dan 
diferensiasi pada nilai untuk uang, 46,0\%. Berdasarkan hasil penelitian ini beberapa konsumen memahami nilai diketahui bahwa keputusan membeli ketika harga rendah. Namun orang lain dibentuk dari atribut produk tersebut. Oleh menganggap nilai ketika ada karena itu persepsi yang baik terhadap keseimbangan antara kualitas dan harga. suatu produk akan menimbulkan Selain itu kemasan dan desain juga keputusan membeli pada mahasiswa. menjadi daya tarik produk untuk menarik Melihat pengaruh dari atribut produk minat konsumen membeli. Menurut terhadap keputusan membeli sebesar Charles A. Bresrin (dalam Kusmayasari, 46,0\%, ini berarti masih terdapat 54,0\% Kumadji, Kusumawati, 2014) pengaruh dari faktor lain, dimana faktorPembungkusan tidak hanya merupakan faktor lain tersebut tidak diteliti dalam pelayanan tetapi juga sebagai salesmen penelitian ini, yaitu: faktor budaya, faktor dan pembawa kepercayaan, dimana suatu sosial dan faktor pribadi.

pembungkus merupakan penglihatan akhir

Hasil penelitian diatas mendukung dari konsumen yang dapat di percaya. hipotesis yang telah diajukan dan sesuai Sedangkan desain produk menurut dengan pendapat para ahli. Mahasiswa Menurut Gitosudarmo (dalam Yulindo, dengan persepsinya menggunakan atribut 2013 J desain atau bentuk produk produk untuk membuat keputusan merupakan atribut yang sangat penting membeli, tetapi bukan hanya itu, masih ada untuk mempengaruhi konsumen agar faktor lain untuk melakukan keputuan konsumen tertarik dan kemudian membeli, karena itu perlu adanya membelinya Adapun setelah kemasan dan generalisasi dari hasil-hasil penelitian ini desain, label produk juga menjadi untuk bisa dilakukan di ruang lingkup yang pertimbangan konsumen membeli produk. lebih besar dengan karakteristik yang Menurut Kotler dan Armstrong (dalam berbeda sehingga perlu dilakukan Yulindo, 2013 ) label berkisar dari penanda penelitian lagi dengan menggunakan atau sederhana yang ditempelkan pada produk menambah variabel-variabel lain yang sampai rangkaian huruf rumit yang belum disertakan dalam penelitian ini. menjadi bagian kemasan. Label juga bisa menggambarkan beberapa hal tentang produk siapa yang membuatnya, dimana produk itu dibuat, kapan produk itu dibuat, kandungannya, cara pemakaiannya, dan bagaimana menggunakan produk itu dengan aman.

Temuan penelitian sejalan dengan teori-teori di atas, dimana penelitian ini membuktikan bahwa munculnya keputusan membeli dapat dipengaruhi oleh atribut produk, dimana dalam penelitian ini diketahui bahwa atribut produk mempengaruhi keputusan membeli sebesar

\section{SIMPULAN}

Berpedoman pada hasil-hasil yang diperoleh dalam penelitian ini, maka dapat disimpulkan terdapat hubungan positif yang signifikan antara atribut dengan keputusan membeli kosmetik pada Mahasiswa Fakultas Psikologi Universitas Medan Area, dengan $\left(r_{x y}=0,678 ; p=\right.$ $0.000<0,05)$. Dari hasil kolerasi ini, maka dapat dinyatakan hipotesis yang diajukan dalam penelitian ini diterima, yaitu semakin baik atribut produk maka 
semakin besar keputusan membeli. Koefisien determinan antara hubungan atribut produk dengan keputusan membeli diperoleh sebesar $\mathrm{r}^{2}=0,460$. Hali ini berarti bahwa sebesar 46,0 \% keputusan membeli yang terjadi dapat dijelaskan dengan menggunakan atribut produk. sisanya sebesar $54,0 \%$ diteransgkan oleh faktor-faktor lain yang tidak diteliti dalam penelitian ini. Diketahui bahwa subjek penelitian yaitu Mahasiswa Fakultas Psikologi Universitas Medan Area memiliki persepsi pada atribut produk yang tergolong sangat tinggi artinya persepsi konsumen terhadap atribut produk oriflame sangat baik, dimana mean hipotetik < mean empirik, yaitu $55<$ 79,701 dan selisihnya lebih dari satu bilangan $S D=9,531$, selain itu juga diketahui bahwa keputusan membeli pada Mahasiswa Psikologi Universitas Medan Area tergolong sangat tinggi artinya sikap konsumen dalam memutuskan membeli produk oriflame sangat tinggi, dimana mean hipotetik < mean empirik , yaitu $60<$ 76,388 dan selisihnya lebih dari satu bilangan $\mathrm{SD}=8,095$.

Berdasarkan hasil penelitian dan kesimpulan, maka berikut hal-hal yang dapat disarankan kepada subjek penelitian konsumen yakni sebelum membeli suatu produk penting untuk diperhatikan setiap informasi yang melekat pada kemasan agar produk tersebut aman saat di pakai. Saran kepada perusahaan kosmetik terutama orifllame penting memperhatikan atribut produk yang meliputi merek, harga, kualitas, desain, kemasan dan label karena melalui atribut produk, konsumen mampu mempersepsikan produk itu baik sehingga akhirnya melakukan keputusan membeli, selain itu juga atribut produk merupakan stimulus bagi konsumen dalam membeli produk. Saran kepada peneliti selanjutnya untuk menyadari masih banyak kekurangan dalam penelitian ini, jadi untuk peneliti selanjutnya jika ingin melakukan penelitian dengan judul yang sama sebaiknya dapat mempertajam teori atribut produk dan keputusan membeli secara lebih rinci dengan menggunakan teori-teori terbaru. Peneliti berharap adanya penelitian lebih lanjut untuk menyempurnakan hasil penelitian ini dengan memperhatikan sampel, yaitu menggunakan sampel orang dewasa atau wanita yang bekerja pada pembelian kosmetik dan lebih memperhatikan dalam pembuatan skala. Bagi peneliti selanjutnya diharapkan agar memperhatikan faktorfaktor lain yang mempengaruhi keputusan membeli seperti, faktor budaya, sosial dan pribadi.

\section{DAFTAR PUSTAKA}

Aditia,F,S. 2012. Faktor-Faktor yang Mempengaruhi Keputusan Pembelian Baju "MINT" Di Counter Java Mall Semarang. Jurnal Sekolah Tinggi Ilmu Ekonomi Widya Manggala

Akbar,K, 2013. Analisis Pengaruh Harga, Brand Image, dan Atribut Produk Terhadap Keputusan Pembelian Handphone atau Smartphone Samsung Jenis Android. Skripsi. Fakultas Ekonomika dan Bisnis : Universitas Diponegoro.

Apsari,F, 2012. Hubungan Antara Kecenderungan narsisme Dengan Minat Membeli Kosmetik Merek Asing Pada Pria Metroseksual, Jurnal Fakultas Ilmu Kesehatan :Universitas Sahid Surakarta Vol. 1 No.2..

Ayu,R.P, 2005. Hubungan Keterlibatan Emosional Dengan Keputusan Membeli Pada Wanita. Skripsi. Fakultas Psikologi : Universitas Islam Indonesia Yogyakarta.

Djamaris, A.RA, 2013. Analisis Faktor Perilaku Konsumen terhadap Atribut Produk dalam Keputusan Pembelian Food Consumer Product. Jurnal Universitas Bakrie, Jakarta

Ferrinadewi,E, 2005. Atribut Produk yang Dipertimbangkan dalam Pembelian 
Kosmetik dan Pengaruhnya pada Kepuasan Konsumen di Surabaya, Jurnal Fakultas Ekonomi, Universitas Kristen Petra Surabaya.Vol.7 No.2.

Haditono, S,R, 2006. Psikologi Perkembangan : Pengantar Dalam Berbagai Bagian. Universitas Gadjah Mada, Yogyakarta.

Hidayat,A.T, Elita,F.M, \& Setiaman,A, 2012. Hubungan Antara Atribut Produk Dengan Minat Beli Konsumen, Jurnal Fakultas Ilmu Komunikasi : Universitas Padjajaran. Vol.1., No.1.

Hurlock, E.B, 1980. Psikologi Perkembangan : Suatu Pendekatan Sepanjang Rentang Kehidupan, Edisi Kelima. Erlangga, Jakarta.

Janah, M.R, 2013. Hubungan Antara Citra Merek Suzuki Dengan Keputusan Pembelian Pada Konsumen Di Dealer Sumber Ayu Mobil Purwokerto, Jurnal Program Studi Psikologi Fakultas Ilmu Kesehatan : Universitas Sahid Surakarta Vol. II, No. 2.

Kusumayasari, Kumadji,S, \& Kusumawati,A, 2014. engaruh Atribut Produk Terhadap Keputusan Pembelian dan Kepuasan Konsumen Green Produk (Survey pada Konsumen Martha Tilaar yang Tergabung dalam Followers Official Account Twitter @Sariayu_MT), Jurnal Fakultas Ilmu Administrasi : Universitas Brawijata Malang.Vol. 14 No. 1.

Lintang,A, Yaningwati,F, \& Wilopo, 2013. Pengaruh Atribut Produk Terhadap Keputusan Pembelian (Survei pada Pelanggan Monopoli Resto dan Cafe Jalan Merbabu Kota Malang). Jurnal Fakultas Ilmu Administrasi : Universitas Brawijaya.

Nurfitriani,A, Wijanarko,B, \& Priyatama,A.N, 2012. Hubungan Antara Citra Merek dan Loyalitas Merek Dengan Pengambilan Keputusan Pembelian Body Lotion Pada Mahasiswi Program Studi Psikologi Universitas Sebelas Maret Surakarta. Jurnal Universitas Sebelas Maret Surakarta: Fakultas Kedokteran.

Raharja,S.W, Arifin,Z, Wilopo, 2013. Pengaruh Psikologi Konsumen Terhadap Keputusan Membeli (Study Pada PT. Winnertech Lintas Nusa). Jurnal Fakultas Ilmu Administrasi : Universitas Brawijaya.

Sangadji,E.M., Sopiah, 2013. Perilaku Konsumen :Pendekatan Praktis Disertai: Himpunan Jurnal Penelitan. C.V Andi Offset, Yogyakarta.

Santrock,J.W, 2003.Adolescence : Perkembangan Remaja. Erlangga, Jakarta.

Sugiyono, 2008. Metode Penelitian Kuantitatif Kualitatif dan R\&D. Alfabeta, Bandung. 2013. Metode Penelitian Kuantitatif Kualitatif dan R\&D. Alfabeta, Bandung.
Tjiptono,F, 2008. Strategi Pemasaran :Edisi III, CV. Andi Offset. Yogyakarta.

Utami,W.B, 2013. Pengaruh Label Halal Terhadap Keputusan Membeli (Survei Pada Pembeli Produk Kosmetik Wardah di Outlet Wardah Griya Muslim An-nisa Yogyakarta). Skripsi. Fakultas Ilmu Sosial dan Humaniora : Universitas Islam Negeri Sunan Kalijaga Yogyakarta.

Vidyarini,T.N, 2007. Representasi Kecantikan Dalam Iklan Kosmetik The Face Shop, Jurnal. Vol.1 No.2. Surabaya.

Wahidah,N, 2013. ArtikelPenelitian :Pengaruh Perilaku Konsumtif Terhadap Gaya Hidup Mahasiswa Pendidikan Ekonomi FKIP UNTAN . Fakultas Keguruan dan Ilmu Pendidikan : Universitas Tanjungpura Pontianak.

Wasitaatmadja, S, M, 1997. Penuntun Ilmu Kosmetik Medik. Universitas Indonesia, Jakarta.

Yulindo,K,P, 2013. Pengaruh Atribut-Atribut Produk Terhadap Keputusan Pembelian Green Produk Cosmetics Sariayu Marta Tilaar Di Kota Padang. Jurnal Fakultas Ekonomi : Universitas Negeri Padang 